\title{
REACTION DYNAMICS OF ELECTRONICALLY EXCITED CALCIUM ATOM*
}

\author{
E. VERDASCO, M. MENÉNDEZ, M. GARAY and A. GONZÁLEZ UREÑA†
}

Departamento de Química Física, Facultad de Ciencias Químicas, Universidad Complutense, 28040-Madrid, Spain and

Unidad de Haces Moleculares y Láseres, Centro de Estudios Avanzados Complutense, C/Isaac Peral, s/n, Universidad Complutense, 28040-Madrid, Spain

\section{O. BENOIST D'AZY, F. J. POBLETE\# ${ }^{*}$ and G. TAIIEB**}

\section{Laboratoire de Photophysique Moleculaire, Université de Paris-Sud,} Bât. 213. Campus d'Orsay, 91405 Orsay Cedex, France

\# and Universidad de Castilla la Mancha, Ciudad Real, Spain **and Université de Rennes I

(Received 1 October 1991; in final form 15 October 1991)

Absolute values of the total chemiluminescence cross-section for the beam-gas $\mathrm{Ca}\left({ }^{3} \mathrm{P},{ }^{1} \mathrm{D}\right)+\mathrm{Cl}_{4} \mathrm{C}$ $\rightarrow \mathrm{CaCl}(\mathrm{A}, \mathrm{B})+\mathrm{Cl}_{3} \mathrm{C}$ and $\mathrm{Ca}\left({ }^{3} \mathrm{P},{ }^{1} \mathrm{D}\right)+\mathrm{SF}_{6} \rightarrow \mathrm{CaF}(\mathrm{A}, \mathrm{B})+\mathrm{SF}_{5}$ reactions have been measured at low collision energy, $E_{T}=0.15$ and $0.14 \mathrm{eV}$, respectively. Both metastable atomic calcium states $\mathrm{Ca}\left({ }^{3} \mathrm{P},{ }^{1} \mathrm{D}\right)$ were produced under low voltage dc-discharge conditions. By changing the discharge conditions, different metastable concentrations were produced to measure the state-to-state cross-section for both ${ }^{3} \mathbf{P}$ and ${ }^{1} \mathbf{D}$ reactions. The following values for the total chemiluminescence cross-sections were obtained:

$$
\begin{aligned}
& \sigma_{1_{\mathrm{D}}}=1.77 \AA \text { and } \sigma_{3_{\mathrm{P}}}=0.25 \AA \text { for the } \mathrm{Ca}\left({ }^{3} \mathrm{P},{ }^{1} \mathrm{D}\right)+\mathrm{Cl}_{4} \mathrm{C} \rightarrow \mathrm{CaCl}(\mathrm{A}, \mathrm{B})+\mathrm{Cl}_{3} \mathrm{C} \text { reaction. } \\
& \sigma_{1_{\mathrm{D}}}=0.59 \AA^{2} \text { and } \sigma_{3 \mathrm{P}}=0.56 \AA^{2} \text { for the } \mathrm{Ca}\left({ }^{3} \mathrm{P},{ }^{1} \mathrm{D}\right)+\mathrm{SF}_{6} \rightarrow \mathrm{CaF}(\mathrm{A})+\mathrm{SF}_{5} \text { reaction. } \\
& \sigma_{1_{\mathrm{D}}}=0.04 \AA^{2} \text { and } \sigma_{3 \mathrm{P}}=0.12 \AA \text { for the } \mathrm{Ca}\left({ }^{3} \mathrm{P},{ }^{1} \mathrm{D}\right)+\mathrm{SF}_{6} \rightarrow \mathrm{CaF}(\mathrm{B})+\mathrm{SF}_{5} \text { reaction. }
\end{aligned}
$$

In addition, beam-beam experiments were carried out at the same average low collision energy that of the beam-gas, and therefore, normalization between both experiments was possible. This procedure allowed us to obtain the excitation function of the $\mathrm{Ca}\left({ }^{1} \mathrm{D}\right)+\mathrm{SF}_{6}$ reaction in absolute values over the $0.15-0.60 \mathrm{eV}$ collision energy range.

On the other hand, by simulation, the ratio of $\mathrm{CaCl}(\mathrm{B}-\mathrm{X} / \mathrm{A}-\mathrm{X})$ emissions intensities was found to be of 0.15 . The variation of this ratio with the relative concentration of ${ }^{1} \mathrm{D} /{ }^{3} \mathrm{P}$ in a Broida oven leads to the conclusion that this state favours the formation of the $\mathrm{B}$ state in the chemiluminescent $\mathrm{Ca}\left({ }^{3} \mathrm{P},{ }^{1} \mathrm{D}\right)+\mathrm{CH}_{3} \mathrm{CHCl}_{2} \rightarrow \mathrm{CaCl}(\mathrm{A}, \mathrm{B})+\mathrm{CH}_{3} \mathrm{CHCl}$ reaction.

\section{INTRODUCTION}

The reaction of alkaline-earth dihalogens and other molecules has been widely studied. ${ }^{1-9}$ Recently, the reactions of electronically excited Ca atoms with group VI hexafluorides $\mathrm{RF}_{6}$, where $\mathrm{R}=\mathrm{S}, \mathrm{Te}, \mathrm{W}$, have attracted considerable attention. ${ }^{1,8-9}$

\footnotetext{
* This work received financial support from CICYT grant no. PB88/146, from the Acción Integrada Hispano-Francesa no. 251/2 and from CNRS GRECO no. 87.

$\dagger$ To whom correspondence should be addressed.
} 
In particular, electronic selectivity of the $\mathrm{Ca}\left({ }^{3} \mathrm{P},{ }^{1} \mathrm{D}\right)$ reactions has been studied with different molecules as $\mathrm{SF}_{6}{ }^{10-11}$ and $\mathrm{N}_{2} \mathrm{O}^{12}$ An important question arises in those reactions where one may have different electronically excited reactants as responsible for the observed chemiluminescence. Two methods can be applied to solve this question: (a) the analysis of the pressure dependence of the chemiluminescence cross-section $^{9}$ or (b) the analysis of the chemiluminescence emission as a function of the metastable concentration which for the two metastable calcium atom states $\left({ }^{3} \mathrm{P},{ }^{1} \mathrm{D}\right)$ has been termed the two state model analysis. ${ }^{10}$

The present paper is an extension of this work to the $\mathrm{Ca}^{*}+\mathrm{RX} \rightarrow \mathrm{CaX} *+\mathrm{R}(\mathrm{X}=\mathrm{Cl}$, $\left.\mathrm{F} ; \mathrm{R}=\mathrm{Cl}_{3} \mathrm{C}, \mathrm{SF}_{5}, \mathrm{CH}_{3} \mathrm{CHCl}\right)$ reactions, where both metastable $\mathrm{Ca}\left({ }^{3} \mathrm{P},{ }^{1} \mathrm{D}\right)$ reactants concentrations were varied by using a low voltage discharge method. ${ }^{13} \mathrm{We}$ anticipate that one of the main results of the present work is the absolute determination of the reaction cross-section for both electronically excited reactions which indicates a clear selectivity favouring the ${ }^{1} \mathrm{D}$ reaction with respect to the $\mathrm{Ca}\left({ }^{3} \mathrm{P}\right)$ one. In addition, normalization of the chemiluminescence yields between beam-gas and beam-beam experiments was carried out to obtain these excitation functions in absolute values.

\section{EXPERIMENTAL}

Part of present experiments were carried out in a beam-gas or beam-beam arrangements using our molecular beam apparatus described elsewhere. ${ }^{9-11}$ Therefore, only a brief description is given here. The atomic calcium oven consists of a stainless steel heated oven where ground state $\mathrm{Ca}$ atoms can be excited to metastable ${ }^{3} \mathrm{P}$ and ${ }^{1} \mathrm{D}$ by a low voltage discharge, whose design can be found elsewhere. ${ }^{12} \mathrm{~A}$ typical oven charge is of the order of $5 \mathrm{~g}$. A $300 \mathrm{~A}$ and $3 \mathrm{~V}$ current was used to vaporize the $\mathrm{Ca}$ metal to the desired temperature. The Ca charge is typically maintained at $1150 \mathrm{~K}$ corresponding to a $\mathrm{Ca}$ vapor pressure of $\approx 5 \mathrm{~T}$ orr, while the source oriffice $(0.5 \mathrm{~mm}$ in diameter) is at $1350 \mathrm{~K}$ (corrected in pyrometer readings). This temperature gradient was achieved by reducing the thickness of the upper part of the heater from $0.25 \mathrm{~mm}$ (lower half of the heater) to $0.18 \mathrm{~mm}$ (upper half of the heater). Under these conditions, runs of 12 hours can be easily achieved. Moreover, a discharge between the heater and the crucible was pulsed using a few microseconds pulse at ca. $2500 \mathrm{~Hz}$ from a Lyons Instruments pulse generator (mod. PG 75 A).

The calcium beam passed into a scattering cell of $24 \mathrm{~mm}$ total length through a collimating hole ( $7 \mathrm{~mm}$ in diameter), located $80 \mathrm{~mm}$ from the viewed source, containing flowing $\mathrm{Cl}_{4} \mathrm{C}$ or $\mathrm{SF}_{6}$ vapor and chemiluminescence was observed perpendicular to the beam at a distance of $90 \mathrm{~mm}$ from the source. Typical background pressures in the source chamber were $10^{-6}$ Torr and pressure never exceded $2 \cdot 10^{-5}$ Torr when the gas was present in the reaction chamber. Table 1 lists the most relevant and typical conditions of the present experiment.

Under the present beam-gas experimental conditions, the reactants' relative velocity can be calculated ${ }^{13}$ by

$$
\bar{V}_{R}=\left(\frac{4}{\pi}\right)^{1 / 2} \sqrt{\frac{2}{\mu} E_{\alpha}}
$$


Table 1 Experimental conditions

\begin{tabular}{ll}
\hline Beam-gas experiments & \\
Oven temp., $\mathrm{K}$ & 1370 \\
Discharge voltage, $\mathrm{V}$ & $30-45$ \\
Discharge current, A & $0.9-1.5$ \\
$\mathrm{Cl}_{4} \mathrm{C}$ pressure, mTorr & $0.4-5$ \\
$\mathrm{SF}_{6}$ pressure, mTorr & 4.3 \\
Average collision energy, eV & $0.15-0.14$ \\
& \\
Broida oven & $\sim 1200$ \\
Crucible temp., $\mathrm{K}$ & $\sim 75$ \\
Discharge voltage, $\mathrm{V}$ & $\sim 0.15$ \\
Discharge current, $\mathrm{A}$ & $\sim 0.5$ \\
$\mathrm{CH}_{3} \mathrm{CHCl}_{2}$ pressure, mTorr & \\
\hline
\end{tabular}

and

$$
\bar{E}_{T}=\frac{2}{3} E_{\alpha}
$$

where $E_{\alpha}$ is given by

$$
E_{\alpha}=\frac{1}{2} \mu\left(\alpha_{g}^{2}+\alpha_{\mathrm{Ca}}^{2}\right)
$$

being $\mu$ the system reduced mass, e.g.

$$
\mu=\frac{m_{g} \cdot m_{\mathrm{Ca}}}{m_{g}+m_{\mathrm{Ca}}}
$$

and $\alpha_{g}\left(g=\mathrm{Cl}_{4} \mathrm{C}\right.$ or $\left.\mathrm{SF}_{6}\right)$ and $\alpha \mathrm{C}_{\mathrm{a}}$ the most probable velocities of the gas cell and the calcium beam, respectively, given by

$$
\alpha_{i}=\left(\frac{2 k T_{i}}{m_{i}}\right)^{1 / 2} \quad\left(i=\mathrm{Cl}_{4}, \mathrm{SF}_{6}, \mathrm{Ca}\right)
$$

For the present experiment, a maxwellian (thermal) Ca beam was assumed. Previous studies ${ }^{12}$ using the same oven and experimental conditions show by time-of-flight determinations that the metastable calcium beam we used has a near maxwelliam velocity distribution. The average collision energy under the present experimental conditions was found to be 0.15 and $0.14 \mathrm{eV}$ for the $\mathrm{Ca}^{*}+\mathrm{Cl}_{4} \mathrm{C}$ and $\mathrm{Ca}^{*}+\mathrm{SF}_{6}$ collisions respectively.

In a second experimental procedure, we used a Broida oven to produce calcium vapor. In the apparatus already described, ${ }^{14}$ calcium is heated in a graphite crucible by a tungsten wire; a cw discharge of $150 \mathrm{~V}$ between the crucible and the ground produces metastable ${ }^{3} \mathrm{P}$ and ${ }^{1} \mathrm{D}$ states which are carried together with ground state Ca by flowing helium at a pressure of 1-5 Torr with a fast pumping (roots $350 \mathrm{~m}^{3} / \mathrm{h}$ ). The atoms are mixed in the reactive zone, which is $40 \mathrm{~cm}$ above the crucible, with the halogenated compound. Fluorescence signal is detected by a monochromator Bausch \& Lomb of $60 \mathrm{~cm}$ focal length, and sent through a boxcar averager to a 
microcomputer. In these experiments, the average speed is almost thermal $(T=400 \mathrm{~K}$, measured by a thermometer), slightly increased by the gas velocity, $\approx 25 \mathrm{~m} / \mathrm{s}$.

Table 1 lists the most relevant and typical conditions of both experiments.

\section{RESULTS AND DISCUSSION}

\section{$\mathrm{Ca}^{*}+\mathrm{Cl}_{4} \mathrm{C}$ and $\mathrm{CH}_{3} \mathrm{CHCl}_{2}$ Systems}

Figure 1 shows the energy levels of the products and reactants for the $\mathrm{Ca}^{*}+\mathrm{Cl}_{4} \mathrm{C}$ reaction. Note that the two chemiluminescent channels (i.e. the $\mathrm{A}$ and $\mathrm{B}$ states of the $\mathrm{CaCl}$ product) are exoergic only if metastable atoms are used, i.e. the process in endoergic for ground state cacium atoms.

In addition, the adiabatic correlation diagramm of the $\mathrm{Ca}+\mathrm{Cl}_{4} \mathrm{C} \rightarrow \mathrm{CaCl}+\mathrm{Cl}_{3} \mathrm{C}$ system using the $\mathrm{C}_{s}$ group of symmetry is also shown in the same figure. It is interesting

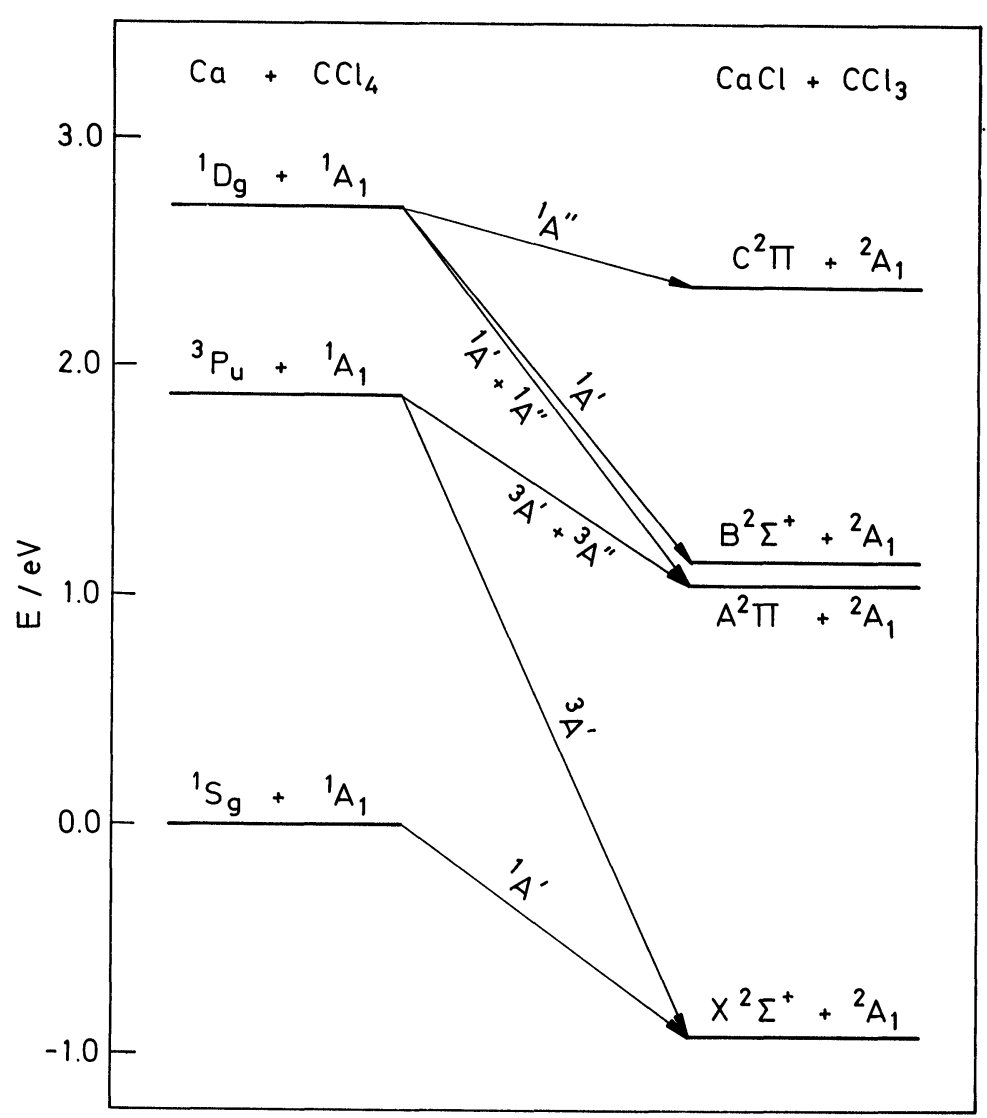

Figure 1 Energy levels for the $\mathrm{Ca}+\mathrm{Cl}_{4} \rightarrow \mathrm{CaCl}+\mathrm{Cl}_{3} \mathrm{C}$ reaction. Energy units in eV. The adiabatic correlation between reactants and products is also shown using the $\mathrm{C}_{\mathrm{s}}$ group of symetry. 
to point out that whereas the $\mathrm{Ca}\left({ }^{1} \mathrm{D}\right)$ state correlates with both $\mathrm{CaCl} \mathrm{A}$ and $\mathrm{B}$ states, the $\mathrm{Ca}\left({ }^{3} \mathrm{P}\right)$ only does with the $\mathrm{CaCl}\left(\mathrm{A}^{2} \Pi\right)$ state.

Figure 2 shows the (low-resolution) chemiluminescence spectrum together with background spectrum when the discharge was turned off. Emission from the two electronic states $\mathrm{A}$ and $\mathrm{B}$ of $\mathrm{CaCl}$ corresponding to transitions $\mathrm{B}^{2} \Sigma^{+} \rightarrow \mathrm{X}^{2} \Sigma^{+}$and $A^{2} \Pi \rightarrow X^{2} \Sigma^{+}$are observed. The spectral shape was found to be independent of $\mathrm{Cl}_{4} \mathrm{C}$

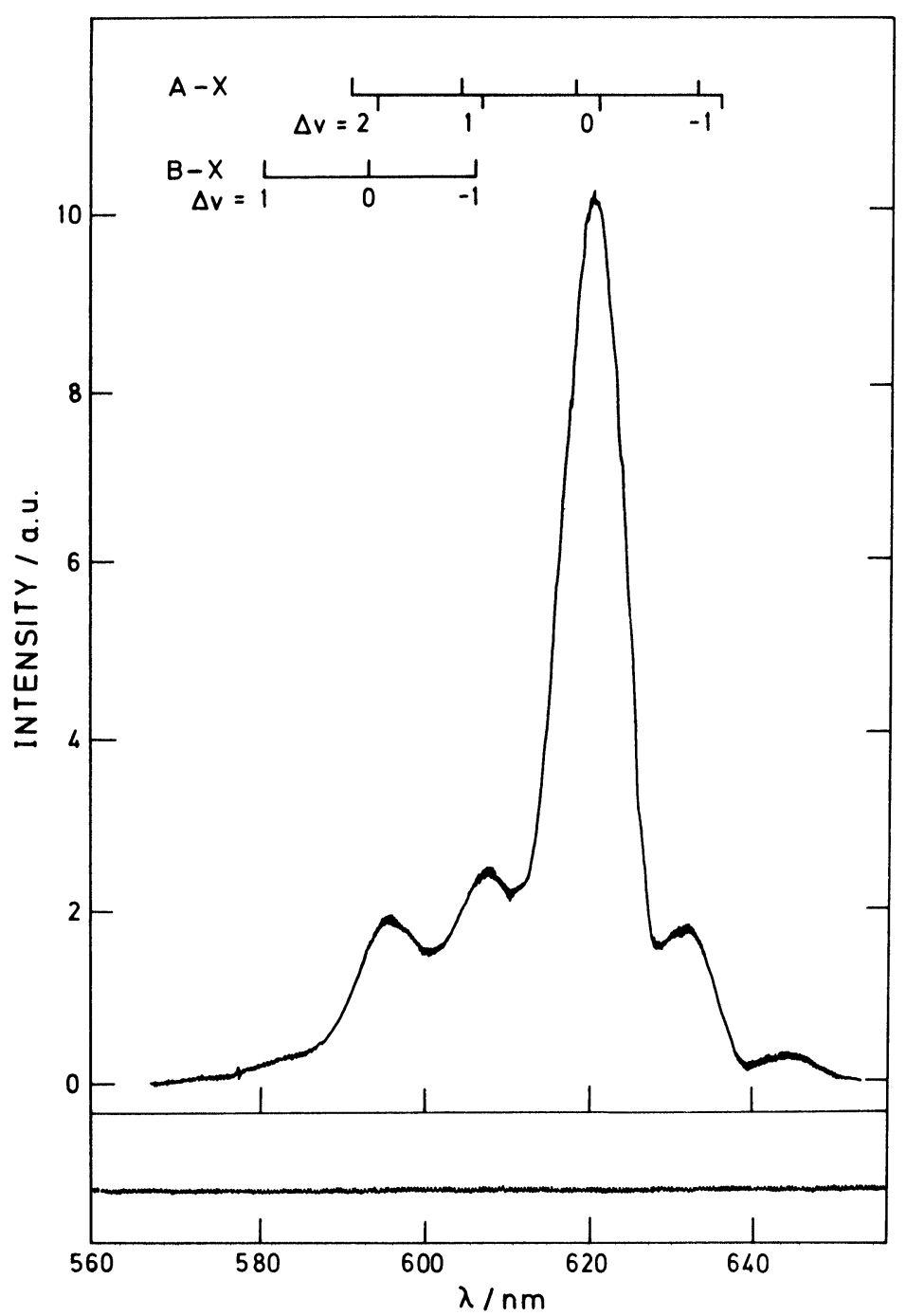

Figure 2 (Top) Chemiluminescence spectrum for the reaction $\mathrm{Ca}\left({ }^{3} \mathrm{P}\right)+\mathrm{Cl}_{4} \mathrm{C}$ at $4.2 \mathrm{mTorr}$. No correction has been made for the spectral response. The peak positions for the $\operatorname{CaCl}\left(\mathrm{B}^{2} \Sigma^{+} \rightarrow \mathrm{X}^{2} \Sigma^{+}\right)$and $\mathrm{CaCl}\left(\mathrm{A}^{2} \Pi \rightarrow \mathrm{X}^{2} \Sigma^{+}\right)$progressions are marked. For the $A$ state, the marks for the ${ }^{2} \Pi_{3 / 2}$ and ${ }^{2} \Pi_{1 / 2}$ are shown. (Bottom) Chemiluminescence spectrum for the background reaction $\mathrm{Ca}\left({ }^{1} \mathrm{~S}\right)+\mathrm{Cl}_{4} \mathrm{C}$ when the discharge was turned off. 
pressure up to $8 \cdot 10^{-3}$ Torr, showing that single-collision conditions applied for the present experiment.

Figure 3 shows the simulation of the A-X and B-X allowing the deconvolution of the experimental spectrum and giving a ratio of $B-X / A-X$ intensities, $R=0.15$.

Figure 4 shows the chemiluminescence spectrum obtained with the Broida oven for the $\mathrm{Ca}^{*}=\mathrm{CH}_{3} \mathrm{CHCl}_{2}$ reaction. Besides the A-X and $\mathrm{B}-\mathrm{X}(\Delta v=0)$ emission which are separated, one observes atomic $\mathrm{Ca}$ transitions coming both from energy pooling and reabsorption from the discharge in the reaction zone. In the same figure is shown the A-X transition deconvoluted from the $5^{3} \mathrm{~S}-4^{3} \mathrm{P}$ line. This deconvolution was used to measure the variation of the ratio $\mathrm{R}$ with the discharge current.

As mentioned before, an important question arises when one considers which state i.e. $\mathrm{Ca}\left({ }^{1} \mathrm{D}\right)$ or $\mathrm{Ca}\left({ }^{3} \mathrm{P}\right)$ is responsible for the observed chemiluminescence. To solve this question two methods can be applied: (a) the analysis of the pressure dependence of the chemiluminescence cross-section ${ }^{9}$ or (b) the analysis of the chemiluminescence emission as a function of the metastable concentration; the so-called two-state analysis model. ${ }^{10}$ In the present work, we have applied the later procedure. Essentially, it consists in measuring the product chemiluminescence as a function of both metastable emission intensities. Under our experimental conditions, it was very difficult to isolate the chemiluminescence yield from both A and B states mainly because the low resolution and the spectral overlapping of the bands. Therefore, we applied the two

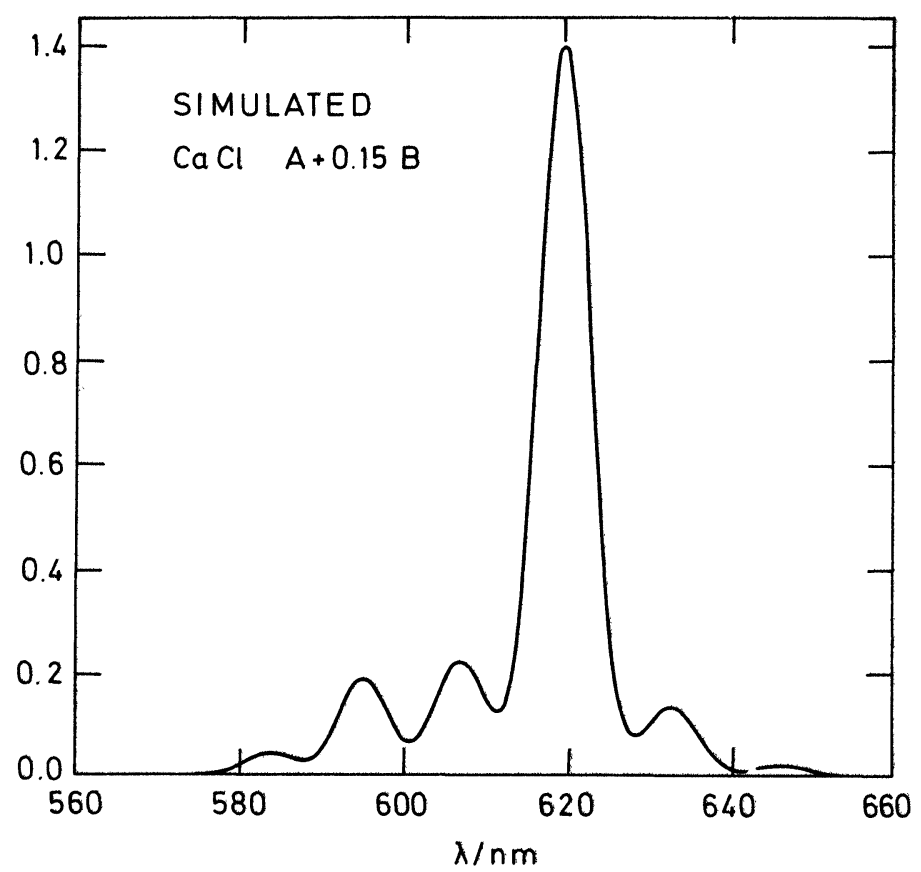

Figure 3 Spectral simulation of the $\mathrm{CaCl} \mathrm{A}-\mathrm{X}$ and $\mathrm{B}-\mathrm{X}$ bands that allows the experimental spectrum deconvolution using a $\mathrm{B}-\mathrm{X} / \mathrm{A}-\mathrm{X}$ intensities ratio of $\mathrm{R}=0.15$. 


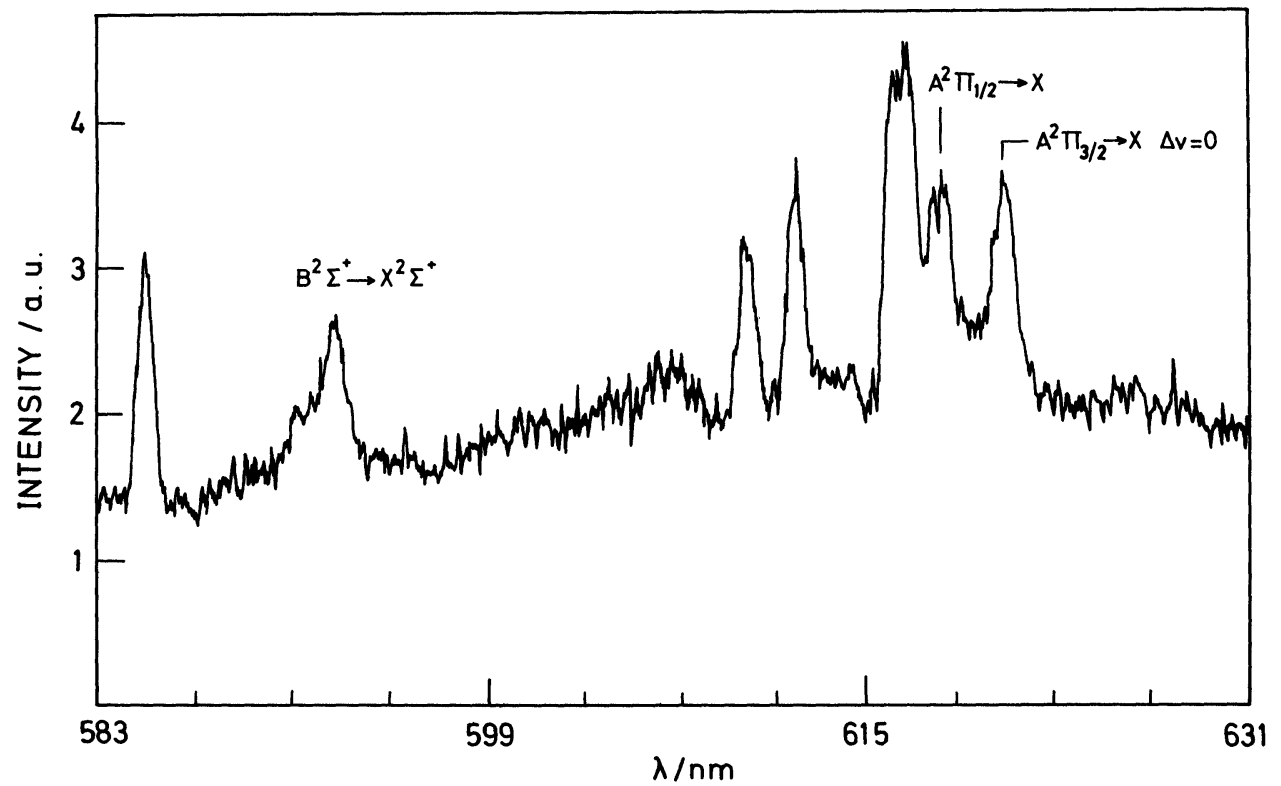

Figure 4 Chemiluminescence spectrum for the $\mathrm{Ca}^{*}+\mathrm{CH}_{3} \mathrm{CHCl}_{2}$ reaction using the Broida oven. Both $\mathrm{A}-\mathrm{X}$ and $\mathrm{B}-\mathrm{X}$ emissions are shown together with the $\mathrm{Ca}$ lines (see text for details).

state model analysis to the entire chemiluminescence yield i.e. the B and A states. following reference, ${ }^{10}$ one can write for the total $\mathrm{CaCl}$ emission intensity, $I_{\text {Cal }}$, the following relation

$$
I_{\mathrm{CaCl}}=n_{\mathrm{Cl}_{4} \mathrm{C}} \bar{V}_{R}\left[\frac{I_{3 \mathrm{P}}}{A_{3 \mathrm{P}} \cdot F_{J=1}} \sigma_{3 \mathrm{P}}+\frac{I_{\mathrm{D}^{\mathrm{D}}}}{A_{1 \mathrm{D}}} \sigma_{\mathrm{I}_{\mathrm{D}}}\right]
$$

where $I_{i}, \sigma_{i}, A_{i}$ are the particular $\left(i={ }^{3} \mathrm{P},{ }^{1} \mathrm{D}\right)$ metastable emission intensity, relative cross-section and atomic transition probability, respectively, and $n_{\mathrm{Cl}_{4} \mathrm{C}}$ and $\bar{V}_{R}$ stand for the number density of the $\mathrm{Cl}_{4} \mathrm{C}$ and relative velocity of the reactants. $F_{J=1}$ is the fraction of ${ }^{3} \mathrm{P}$ in the $J=1$ level, found experimentally ${ }^{10}$ equal to 0.3 .

Equation (6) can be rearranged as follows:

$$
\frac{I_{\mathrm{CaCl}^{*}}}{n_{\mathrm{Cl}_{4} \mathrm{C}} \bar{V}_{R} I_{\mathrm{I}_{\mathrm{D}}}}=\frac{I_{3 \mathrm{P}}}{I_{\mathrm{I}_{\mathrm{D}}} A_{3 \mathrm{P}} F_{\mathrm{J}=1}} \cdot \sigma_{3 \mathrm{P}}+\frac{\sigma_{\mathrm{I}_{\mathrm{D}}}}{A_{\mathrm{I}_{\mathrm{D}}}}
$$

Therefore, a plot of $I_{\mathrm{CaCl}^{1}} / n_{\mathrm{Cl}_{4} \mathrm{C}} \bar{V}_{R} I_{\mathrm{D}_{\mathrm{D}}}$ versus $I_{\mathrm{P}_{\mathrm{P}}} / I_{\mathrm{D}}$ should give a straight line with a slope, $s$ :

$$
s=\frac{\sigma_{3 \mathrm{P}}}{A_{3_{\mathrm{P}}} F_{\mathrm{J}=1}}
$$

and an intercept, $i$ :

$$
i=\frac{\sigma_{\mathrm{I}_{\mathrm{D}}}}{A_{\mathrm{I}_{\mathrm{D}}}}
$$


The lifetimes of the metastable states $\tau\left[\mathrm{Ca} *\left({ }^{3} \mathrm{P}-{ }^{1} \mathrm{~S}\right)\right]=A_{3_{\mathrm{P}}}{ }^{-1}$ and $\tau\left[\mathrm{Ca} *\left({ }^{1} \mathrm{D}-{ }^{1} \mathrm{~S}\right)\right]$ $=A_{{ }^{1}}{ }^{-1}$ are known to be $0.44 \mathrm{~ms}$ and $25 \mathrm{~ms}$, respectively. ${ }^{10}$ Since we found from laser induced fluorescence measurements that $F_{J=1}=0.3$, the following values for the total chemiluminescence reaction $\mathrm{Ca}^{*}+\mathrm{Cl}_{4} \mathrm{C} \rightarrow \mathrm{CaCl}(\mathrm{A}, \mathrm{B})+\mathrm{Cl}_{3} \mathrm{C}$ were obtained $\sigma_{1 \mathrm{D}}=1.77 \AA^{2}$ and $\sigma_{3 \mathrm{p}}=0.25 \AA^{2}$ from the linear plot of Figure 5. The difference in the reaction cross-section indicates a clear electronic selectivity in the chemiluminescence channel although more beam-beam experiments changing the collision energy, as well as the electronic excitation would be necessary to confirm this feature of the reaction dynamics.

A similar procedure was used with the Broida oven to check the electronic selectivity observed in the beam-gas experiment, but now for the $\mathrm{Ca}^{*}+\mathrm{CH}_{3} \mathrm{CHCl}_{2}$ reaction.

First, we measured the intensities ratio of the $4 p^{1} \mathrm{P}-3^{1} \mathrm{D} / 5^{3} \mathrm{~S}-4^{3} \mathrm{P}$ lines observed in the reaction zone at $6717 \AA$, and $6102 \AA, 6122 \AA$ and $6162 \AA$ respectively. The same transitions were also recorded in the discharge itself with a small monochromator and the response of the two monochromators adjusted by using a commercial Calcium-Neon hollow cathode. Assuming that the upper states of the transitions are formed by absorption of resonance photons coming from the discharge and taking into account the radiative lifetime of both ${ }^{1} \mathrm{D}$ and ${ }^{3} \mathrm{P}$ states, after correction of the photomultiplier responses, the ratio $\left({ }^{1} \mathrm{D} /{ }^{3} \mathrm{P}\right)$ is found to be $\rho=0.31$ at maximum current in the cw discharge (150 ma).

In a second procedure, we have measured the intensities ratio of the two forbidden transitions ${ }^{1} \mathrm{D}-{ }^{1} \mathrm{~S}$ and ${ }^{3} \mathrm{P}-{ }^{1} \mathrm{~S}$ at $4575 \AA$ and $6572 \AA$ respectively. Taking into account the radiative lifetimes again, and after photomultiplier response correction, we found

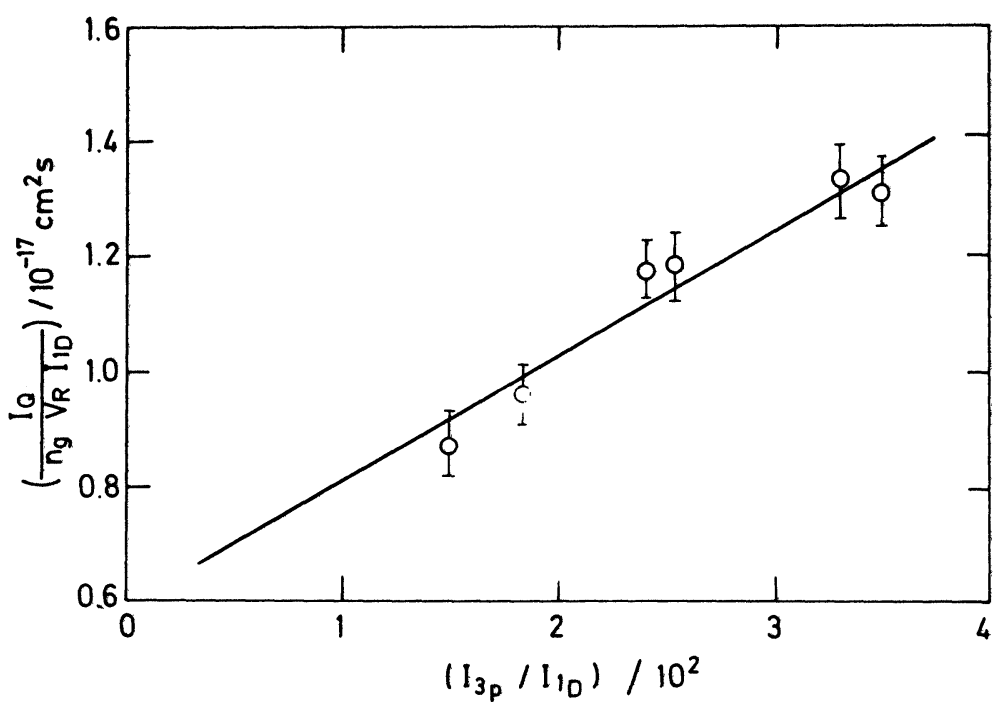

Figure 5 Product chemiluminescence $I_{Q}$ reduced by $n_{\mathrm{Cl}_{4} \mathrm{C}} \bar{V}_{R} I_{\mathrm{I}_{\mathrm{D}}}$ as a function of $I_{3 \mathrm{p}} / I_{\mathrm{D}}$ for the $\mathrm{Ca}^{*}+\mathrm{Cl}_{4} \mathrm{C}$ reaction. This is equation (7) type of plot from which slope and intercept both reaction cross-sections were obtained (see text for comments). 


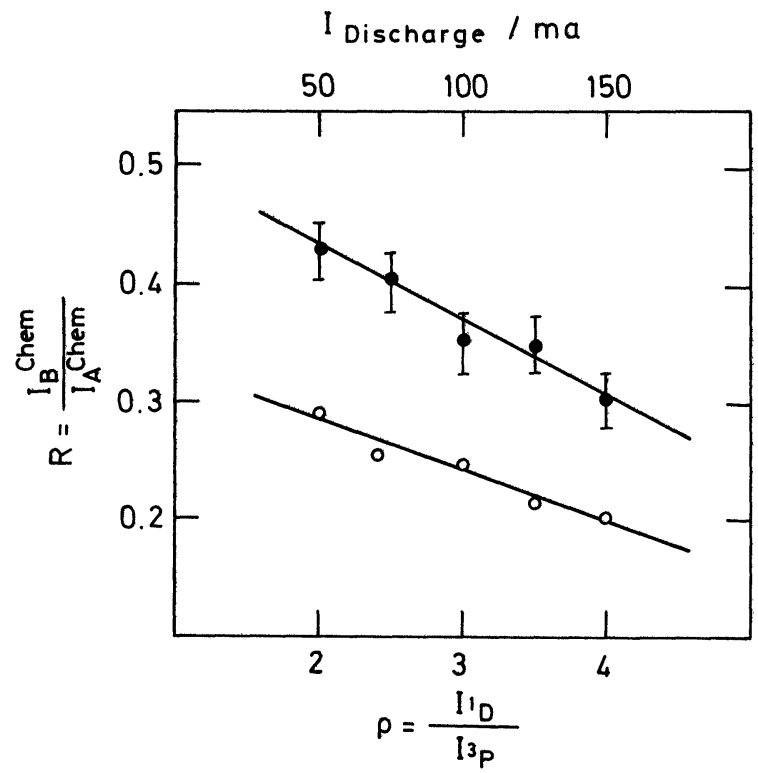

Figure $6 \mathrm{CaCl}^{*} \mathrm{~B}-\mathrm{X} / \mathrm{A}-\mathrm{X}$ intensity ratio, $\mathrm{R}$, as a function of the ${ }^{1} \mathrm{D} /{ }^{3} \mathrm{P}$ intensity ratio obtained by changing the discharge current. The data is obtained from the $\mathrm{Ca}^{*}+\mathrm{CH}_{3} \mathrm{CHCl}_{2}$ reaction.

$\rho=0.10$ at maximum current. This is not the value obtained by the first procedure, indicating that we have to take into account other mechanisms like energy pooling for the formation of excited species.

We then measured the variation of $\rho$ with the intensity of the discharge current, and the variation of $R$ with the current. The results are shown on the Figure 6. One can clearly see that the B-X intensity increases with ${ }^{1} \mathrm{D}$ concentration, which confirms the electronic selectivity found in the beam-gas experiments.

$C a^{*}+S F_{6}$ System

Figure 7 shows the low resolution spectrum together with background spectrum when the discharge was turned off. The low-lying electronic states of $\mathrm{CaF}$ and available reaction energies in the $\mathrm{Ca}^{*}+\mathrm{SF}_{6}$ can be found in Ref. 9 and 10. Emission from the two electronic states $\mathrm{A}$ and $\mathrm{B}$ of $\mathrm{CaF}$ corresponding to transitions $\mathrm{B}^{2} \Sigma^{+} \rightarrow$ and $\mathrm{A}^{2} \Pi \rightarrow \mathrm{X}^{2} \Sigma^{+}$are observed. No emission from the C-X band $\left(\lambda_{\max }=330.9 \mathrm{~nm}\right)$ was observed under the present experimental conditions. As in the previous case, the spectral shape was found independent of $\mathrm{SF}_{6}$ pressure over the $0.8-8 \mathrm{mT}$ Torr range, showing that single-collision conditions applied for the present experiment.

Absolute chemiluminescence cross-section were obtained by the same procedure outlined above, e.g. changing the metastable density ratio. Linear plots of the form described by equation (7) are shown in Figure 8 for both A and B bands of CaF. Indeed, Table 2 summarizes the present absolute determinations as well as a previously reported data on similar reactions. 


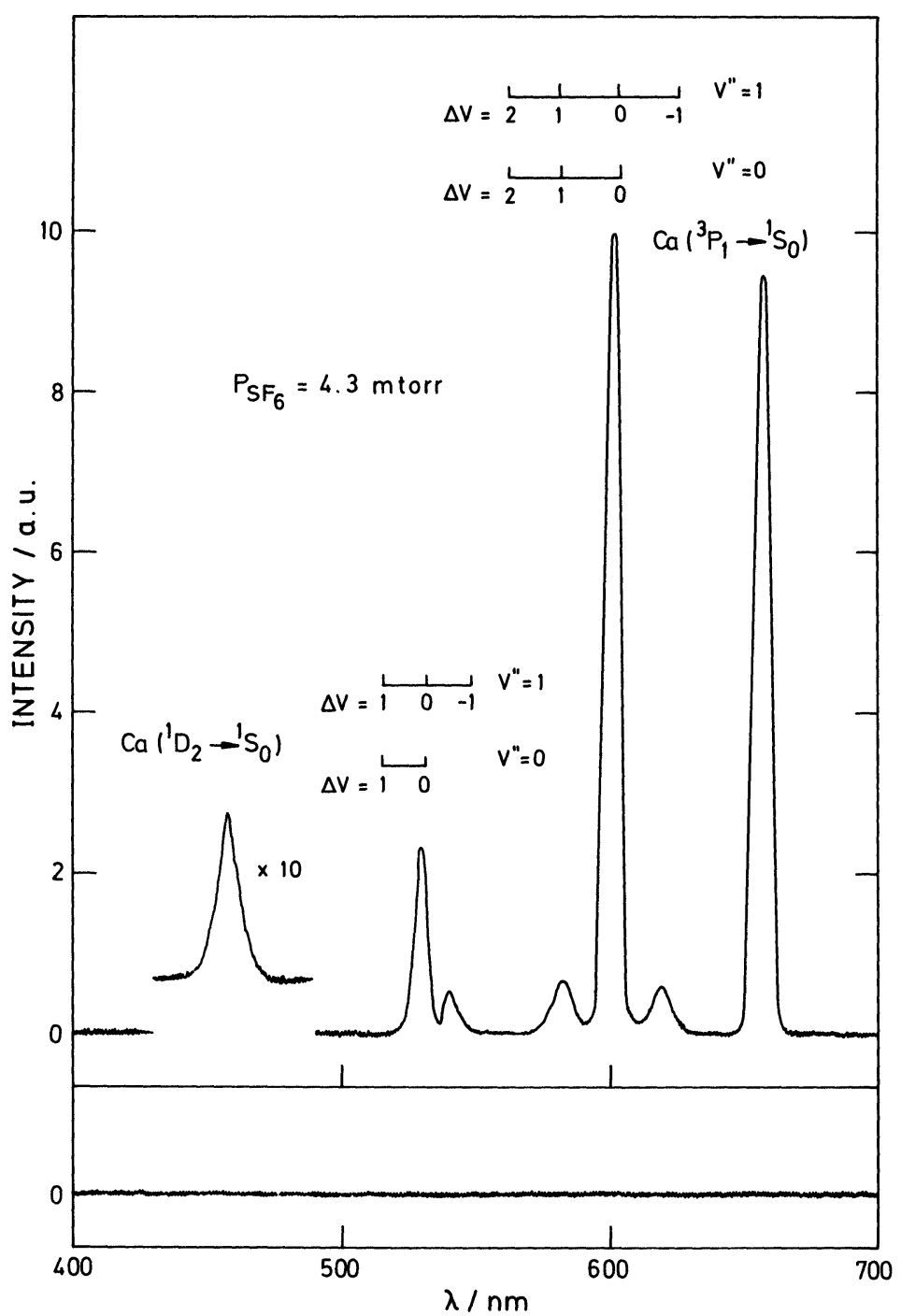

Figure 7 (Top) Chemiluminescence spectrum for reaction of $\mathrm{Ca}\left({ }^{3} \mathrm{P},{ }^{1} \mathrm{D}\right)+\mathrm{SF}_{6}$ at $4.3 \mathrm{mT}$ Torr. No correction has been made for the spectral response. The peak positions for the $\left.\mathrm{CaF}\left(\mathrm{B}^{2} \Sigma^{+} \rightarrow \mathrm{X}^{2} \Sigma^{+}\right) \mathrm{CaFA}^{2} \Pi \rightarrow \mathrm{X}^{2} \Sigma^{+}\right)$ progressions are marked. (Bottom) Chemiluminescence spectrum for the background reaction $\mathrm{Ca}\left({ }^{1} \mathrm{~S}\right)+\mathrm{SF}_{6}$ when the discharge was turned off.

The importance of the beam-gas experiment is the knowledge of density of reactive gas. On the other hand, in the beam-beam experiment, absolute values of the supersonic beam densities are unknown and only relative values of the ratio $\sigma_{3 \mathrm{p}} / \sigma_{\mathrm{I}_{\mathrm{D}}}$, as a function of the collision energy, can be determined. Nevertheless, if a beam-beam 

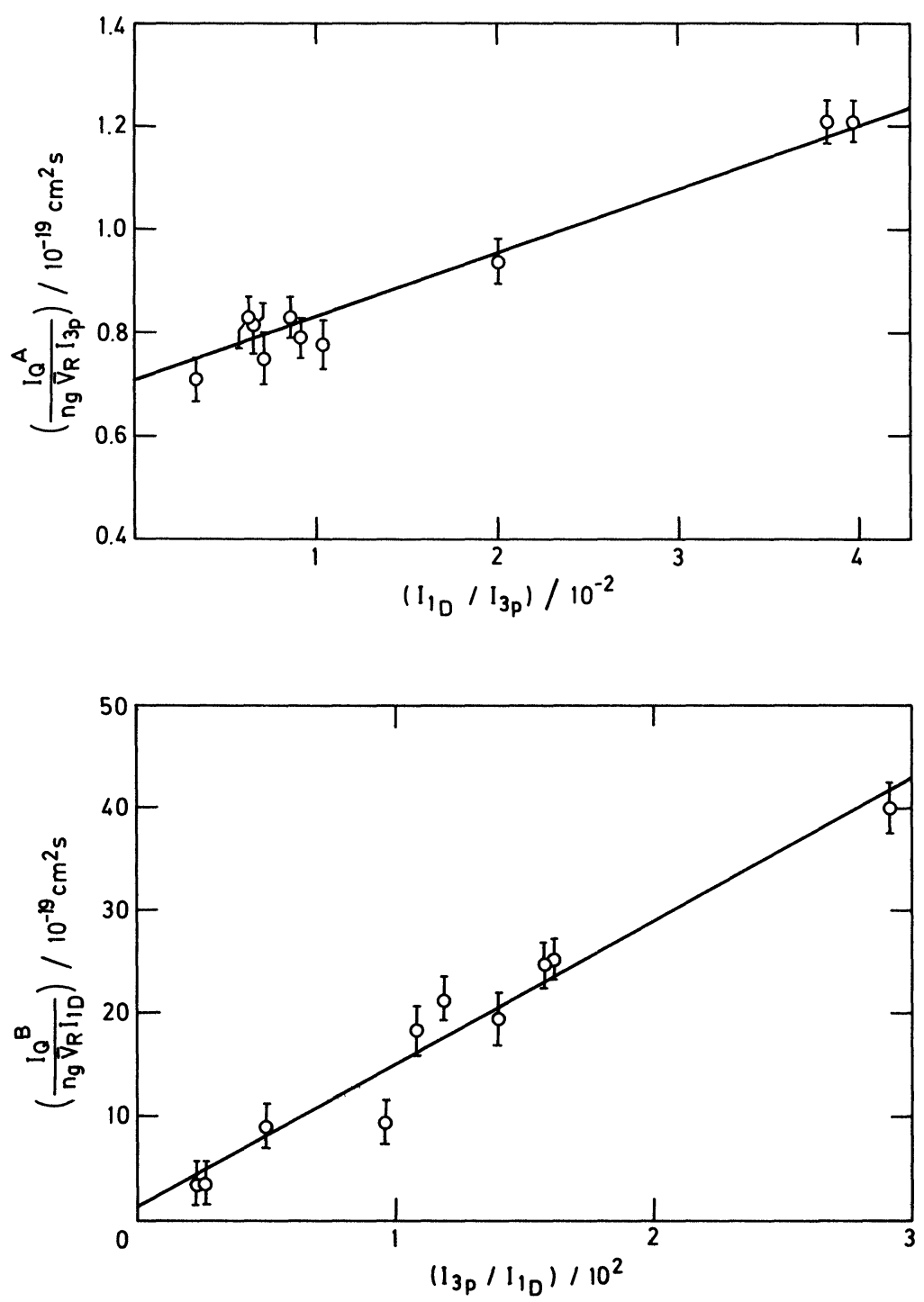

Figure 8 Same presentation as in Figure 5 but for the $\mathrm{Ca}^{*}+\mathrm{SF}_{6}$ reaction. (Top) $\mathrm{CaF}$ A-X band emission. (Bottom) CaF B-X band emission.

experiment at low enough collision energy is carried out at the same average collision energy that of the beam-gas, normalization between both experiments is possible. This procedure was carried out to obtain the excitation function of the $\mathrm{Ca}\left({ }^{1} \mathrm{D}\right)+\mathrm{SF}_{6}$ reaction in absolute values, as displayed in Figure 9 over $0.15-0.60 \mathrm{eV}$ of collision energy range. 
Table 2 Values of the reaction cross-section for several calcium atom reactions

\begin{tabular}{lll}
\hline Reaction & $\sigma_{\mathrm{R}} / \AA^{2}$ & Ref. \\
\hline $\mathrm{Ca}\left({ }^{3} \mathrm{P}\right)+\mathrm{SF}_{6} \rightarrow \mathrm{CaF}(\mathrm{A})+\mathrm{SF}_{5}$ & 0.54 & (a) \\
$\mathrm{Ca}\left({ }^{3} \mathrm{P}\right)+\mathrm{SF}_{6} \rightarrow \mathrm{CaF}(\mathrm{B})+\mathrm{SF}_{5}$ & 0.12 & (a) \\
$\mathrm{Ca}\left({ }^{1} \mathrm{D}\right)+\mathrm{SF}_{6} \rightarrow \mathrm{CaF}(\mathrm{A})+\mathrm{SF}_{5}$ & 0.59 & (a) \\
$\mathrm{Ca}\left({ }^{1} \mathrm{D}\right)+\mathrm{SF}_{6} \rightarrow \mathrm{CaF}(\mathrm{B})+\mathrm{SF}_{5}$ & 0.04 & (a) \\
$\mathrm{Ca}\left({ }^{3} \mathrm{P}\right)+\mathrm{Cl}_{4} \mathrm{C} \rightarrow \mathrm{CaCl}+\mathrm{Cl}_{3} \mathrm{C}$ & 0.25 & (a) \\
$\mathrm{Ca}\left({ }^{1} \mathrm{D}\right)+\mathrm{Cl}_{4} \mathrm{C} \rightarrow \mathrm{Cl} \mathrm{Cl}_{3} \mathrm{C}$ & 1.77 & (a) \\
$\mathrm{Ca}\left({ }^{3} \mathrm{P}\right)+\mathrm{N}_{2} \mathrm{O}+\mathrm{CaO}+\mathrm{N}_{2}$ & 4.80 & (b) \\
$\mathrm{Ca}\left({ }^{1} \mathrm{D}\right)+\mathrm{N}_{2} \mathrm{O} \rightarrow \mathrm{CaO}+\mathrm{N}_{2}$ & 3.60 & (b) \\
\hline
\end{tabular}

(a) Present work

(b) J. A. Irvin and P. J. Dagdigian, J. Chem. Phys. 74, 6178 (1981)

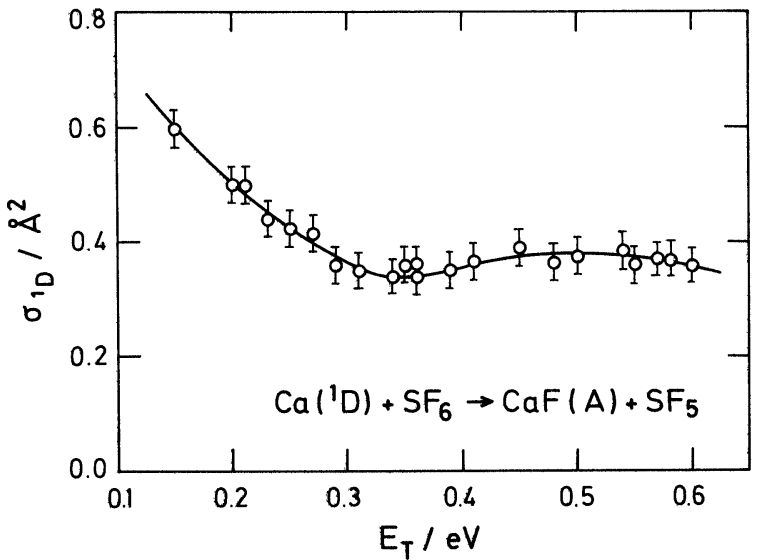

Figure 9 Chemiluminescence excitation function in absolute values for the $\mathrm{Ca}\left({ }^{1} \mathrm{D}\right)+\mathrm{SF}_{6}$ reaction (see text for comments).

A Comparison between the Pressure Dependence and Metastable Ratio Change Method in Beam-gas Chemiluminescence

The present $\sigma_{\mathrm{ID}}$ and $\sigma_{3 \mathrm{p}}$ values for the $\mathrm{Ca}^{*}+\mathrm{SF}_{6}$ reaction are in disagreement without previous data from Ref. 9. The main difference consists of whereas the present values were obtained by the metastable ratio method, those of Ref. 9 were obtained by the pressure dependence method. A comparison between both procedures seems therefore necessary.

Equation (7) can give the following expressions:

$$
\sigma_{3 \mathrm{P}}=\frac{I_{Q}}{n_{g} \bar{V}_{R} n_{3 \mathrm{P}}}-\frac{n_{1 \mathrm{D}}}{n_{3 \mathrm{P}}} \cdot \sigma_{1 \mathrm{D}}
$$




$$
\sigma_{1_{\mathrm{D}}}=\frac{I_{Q}}{n_{g} \bar{V}_{R} n_{1 \mathrm{D}}}-\frac{n_{3 \mathrm{P}}}{n_{1 \mathrm{D}}} \cdot \sigma_{3 \mathrm{P}}
$$

where each $n_{i} \equiv I_{i} / A_{i}$

These two equations can be re-written as

$$
\begin{aligned}
& \sigma_{3 \mathbf{P}}=\sigma_{3 \mathbf{P}}^{\prime}-\frac{n_{1_{\mathrm{D}}}}{n_{3 \mathbf{P}}} \cdot \sigma_{{ }^{\mathrm{D}}} \\
& \sigma_{{ }^{\mathrm{D}}}=\sigma_{\mathbf{I}_{\mathrm{D}}}^{\prime}-\frac{n_{3_{\mathbf{P}}}}{n_{\mathbf{I}_{\mathbf{D}}}} \cdot \sigma_{{ }^{\mathbf{P}}}
\end{aligned}
$$

where the prime stands for the cross-sections value

$$
\sigma_{i}^{\prime}=\frac{I_{Q}}{n_{g} \bar{V}_{R} N_{i}}
$$

i.e. the formula used in Ref. 9 where the pressure dependence method was used. After inspection of the above equations, one can realize that in those situations when $n_{1} / n_{3 p} \ll 1$ both the new (present results) and the old value of the reaction cross-section are almost identical (very different) for the $\mathrm{Ca}\left({ }^{3} \mathrm{P}\right)$ reaction $\left(\mathrm{Ca}\left({ }^{1} \mathrm{D}\right)\right.$ reaction). Furthermore, in the case when $n_{3 \mathrm{p}} / n_{\mathrm{I}_{\mathrm{D}}} \gg 1$, one can expect a much higher uncertainty in extracting $\sigma_{1_{\mathrm{D}}}$ from the pressure dependence method.

These considerations could justify the conflict between the present and old $\sigma_{\mathbf{I}^{\mathrm{D}}}$ values while they indicate that the present values based on a direct change of both metastable concentration should give more reliable data.

\section{CONCLUDING REMARKS}

This paper centers its attention on the reaction dynamics of electronically excited alkaline earth atoms using two different but complementary techniques, e.g. the beam-gas or beam-beam method and the Broida (bulk) method.

An important common feature of both approaches is the experimental method to change the metastable ratio of the atomic calcium. By changing the discharge conditions, one is able to modify the ${ }^{3} \mathrm{P} /{ }^{1} \mathrm{D}$ metastable ratio and therefore to isolate the electronic selectivity associated to each metastable reactants. This procedure has been carried out in both techniques giving consistent results about the electronic energy dependence (electronic selectivity) of the total reaction cross-section in the $\mathrm{Ca}\left({ }^{3} \mathrm{P},{ }^{1} \mathrm{D}\right)+\mathrm{RCl}\left(\mathrm{R}=\mathrm{Cl}_{3} \mathrm{C} \cdot, \mathrm{CH}_{3} \mathrm{CHCl} \cdot\right) \rightarrow \mathrm{CaCl}+\mathrm{R} \cdot$ chemiluminescent reactions.

On the other hand, another interesting aspect of the present work is the use of beam-bas experiments, where the density gas is known, to normalize beam-beam reaction cross-section data. This procedure originally provides excitation function data of electronically excited species in absolute values, as shown for the $\mathrm{Ca}\left({ }^{1} \mathrm{D}\right)+\mathrm{SF}_{6} \rightarrow \mathrm{CaF}^{*}+\mathrm{SF}_{5}$ reaction 


\section{Acknowledgements}

We would like to thank F. Fethi for his help in the Broida type experiments.

\section{References}

1. E. Verdasco, Ph. Thesis, Universidad Complutense de Madrid, Junio 1989.

2. M. Menzinger, Adv. Chem. Phys. 42, 1 (1980). See also M. Menzinger in Selectivity in Chemical Reactions (J. C. Whitehead, ed.), Kluver Academic Publishers, pp. 457 (1988).

3. A. Kowalski and M. Menzinger, Chem. Phys. Lett. 78, 461 (1981).

4. T. Kiang, R. C. Estler and R. N. Zare, J. Chem. Phys. 70, 5925 (1979).

5. T. Kiang and R. N. Zare, J. Am. Chem. Soc. 102, 4042 (1980).

6. P. J. Dagdigian, Chem. Phys. Lett. 55, 239 (1978).

7. M. L. Campbell, N. Furio and P. J. Dagdigian, Laser Chem. 6, 391 (1986).

8. (a) A. Kowalski and M. Mezinger, J. Phys. Chem. 92, 4191 (1988). (b) F. Engelke and K. H. Meiwes-Broer in Selectivity in Chemical Reactions (J. C. Whitehead, ed.), Kluver Academic Publishers, pp. 135 (1988).

9. E. Verdasco, V. Sáez Rábanos, F. J. Aoiz and A. González Ureña, J. Phys. Chem. 91, 2073 (1987).

10. E. Verdasco, V. Sáez Rábanos and A. González Ureña, Laser Chem. 10, 51 (1989).

11. E. Verdasco and A. González Ureña, Chem. Phys. Lett. 169, 437 (1990). See also ibid, J. Chem. Phys. 93, 428 (1990).

12. A. González Ureña, E. Verdasco Costales and V. Sáez Rábanos, Meas. Sci. Technology, 1, 250 (1990).

13. P. J. Dagdigian, H. W. Cruse and R. N. Zare, J. Chem. Phys. 62, 1824 (1975).

14. See for example J. Rostas, N. Shafrzadeh, G. Täieb, B. Bourguignon and M. G. Prisant, Chem. Phys. 142, 97 (1990) and references cited therein. 